\title{
Sinfonia para a solidão (2019-2021): Poetic approach of multisensory processes in the pandemic context
}

\author{
Keywords \\ Art and Acience, Bioplastic, Multisensory Processes, New Media Art, Wearable.
}

"Sinfonia para a Solidão" (Symphony for the Solitude) is a wearable that detects social distance between the wearer and other human bodies, expressing it through tactile and auditory stimuli. Two sensors calculate the distance and presence of individuals nearby. If an approach is detected, the skin of the user is stimulated by the vibration of micro-motors, and sounds are played by a small speaker attached to the wearable. The material that composes the garment is made of tapioca bioplastic with the insertion of cinnamon, turmeric, and dried chamomile tea leaves, adding a layer of smells and textures to the work. "Sinfonia para a Solidão" is an experiment that explores the multisensory perception addressing this topic by considering different social, political, and cultural contexts. The piece aims at discussing the loneliness resulting from the need for social isolation due to the Pandemic triggered by COVID-19. It alerts the approximation of others by emitting audible warnings. At the same time, it comforts the user with vibrations on the skin and with the smell of herbs that alludes to private protected environment and homemade food. It is a symphony of stimuli to address the physical and psychological consequences of social distancing, as well as to warn about the danger of the virus contamination, which occurs mainly through proximity and direct contact among people. The creative process for the concept and design of the wearable occurred in the context of social distancing policies. Therefore, the development of the experiment was highly influenced by the
"Do it Yourself" (DIY) culture and information shared by the on-line community. The technical part of the piece was built on the open-source platform Arduino, and the investigation of the tapioca bioplastic was influenced by the recipe shared by Rafaela Blanch Pires and Helena Kussik from AdaLab/UFG (Federal University of Goiás/ Brazil). The use of the bioplastic from manioc flour (tapioca) is environmentally friendly, and it also reflects how Brazilian food heritage can influence new media art. The experiment was developed during a $\mathrm{PhD}$ research that was focused on the research of Multisensory Processes through the association of art, science, and technology. The main objective of the investigation was to identify the art contributions to the topic. The results suggest that artists can do so by expanding this research into different social, cultural, and political contexts. "Sinfonia para a Solidão" was created within this framework, and it is related to a series of artistic experiments that investigates multisensory perception by developing wearables, such as "Spiel", by Peter van Haaften \& Michael Montanaro (2019), "Neoteny" by Hui Sim Chan (Sim) (2018) and "SHE BON" by Sarah Petkus (2018). The relation between theory and practice was explored by bibliographic survey of the theme on both scientific and artistic contexts, as well as by the analysis of artworks and the development of poetic experiments. These hybrid research process resulted in a close dialog between artistic and theoretical references. 